BARBOSA, Carlos Alberto Sampaio. Fotojornalistas brasileiros em época de ditadura: entre a estabilidade e o compromisso. Domínios da imagem, v. 13, n. 24, p. 86-103, jan./jun. 2019.

Recebido em 1/9/2019 e aprovado em 16/11/2019

\title{
FOTOJORNALISTAS BRASILEIROS EM ÉPOCA DE DITADURA: ENTRE A ESTABILIDADE E O COMPROMISSO
}

\section{BRAZILIAN PHOTOJOURNALISTS IN TIMES OF DICTATORSHIP: BETWEEN STABILITY AND COMPROMISE}

Carlos Alberto Sampaio Barbosa

Resumo: A proposta deste artigo é analisar a trajetória de três fotógrafos de imprensa brasileiros durante o período da ditadura militar brasileira em particular as atuações em terras latino-americanas. Pretendemos observar quais são os principais temas fotografados, suas abordagens, relação com os veículos de informação e interação com o universo fotográfico do continente. A proposta é verificar como se transforma o olhar destes fotógrafos brasileiros, como se deu sua produção visual e o que é publicado. Metodologicamente a proposta procurar cruzar as fontes hemerográficas com história oral e também com os arquivos destes fotógrafos. A hipótese principal é que os fotógrafos não só produziram representações dos acontecimentos, mas tiveram um papel relevante na resistência aos regimes militares e na luta pela redemocratização.

Palavras-chave: Fotojornalismo; Ditadura Militar; Imprensa; América Latina

\begin{abstract}
The purpose of this article is to analyze the trajectory of three Brazilian press photographers during the period of the Brazilian military dictatorship, particularly the performances in Latin American lands. We intend to observe what are the main subjects photographed, their approaches and relationship with the vehicles of information and interaction with the photographic universe of the continent. The proposal is to verify how the look of these Brazilian photographers is transformed, how their visual production took place and what is published. Methodologically the proposal seeks to cross the hemerographic sources with oral history and also with the archives of these photographers. The main hypothesis is that photographers not only produced representations of events, but played an important role in resisting military regimes and in the struggle for redemocratization.
\end{abstract}

Keywords: Photojournalism; Military Dictatorship; Press; Latin America.

\footnotetext{
- Professor de História das Américas no Departamento de História e do Programa de Pósgraduação em História da Faculdade de Ciências e Letras Campus de Assis da Universidade Estadual Paulista. Coordena o grupo de Pesquisa História Visual, Artistas e Intelectuais. Suas áreas de atuação são a Fotografia e História Visual Latino-americana e História Mexicana. Email para contato carlos.as.barbosa@unesp.br
} 
BARBOSA, Carlos Alberto Sampaio. Fotojornalistas brasileiros em época de ditadura: entre a estabilidade e o compromisso. Domínios da imagem, v. 13, n. 24, p. 86-103, jan./jun. 2019.

\section{Introdução}

Os estudos sobre os regimes militares na América Latina vêm produzindo importantes aportes de investigação nos últimos anos. Apresenta-se como um campo historiográfico consistente, que aborda um passado recente e carrega as marcas de um período traumático e autoritário. No caso brasileiro, 2014 foi um ano de muitas publicações, por conta dos 50 anos do golpe, e na Argentina, em 2016, completou-se 40 anos da tomada do poder pelos militares, para citar apenas dois exemplos. Ao longo das últimas décadas as jovens democracias latino-americanas passaram por um lento processo de redemocratização, com muitos percalços pelo caminho. A temática dos direitos humanos e os embates pela memória desse período ainda estão em disputas. A fotografia e o fotojornalismo não ficaram ausentes dessa luta; muito pelo contrário, desempenhou um papel fundamental no combate contra o autoritarismo, na luta pela democracia, na elaboração de uma visibilidade de distintos atores políticos e sociais e na construção de todo um imaginário nas diversas sociedades latino-americanas.

O objetivo desse texto é apresentar avanços de uma pesquisa maior que procura investigar o papel dos fotógrafos documentais e fotojornalistas brasileiros durante a ditadura militar, em particular seu olhar para a América Latina, especialmente no registro eventos políticos. Cabe salientar que nesse período um número considerável de fotógrafos se deslocaram pela região produzindo um conjunto significativo de imagens.

A proposta da pesquisa é verificar como se transforma o olhar dos fotógrafos brasileiros, como se deu sua produção visual e o que é publicado pela imprensa ao longo do regime militar. Do ponto de vista metodológico a proposta da pesquisa visa cruzar as fontes hemerográficas (periódicos brasileiros que privilegiaram a fotografia) com história oral (entrevistas com editores de fotografia e fotógrafos que atuaram nesse período) e também, quando possível, com os arquivos destes fotógrafos.

Algumas perguntas que a investigação procura responder são: como os repórteres fotográficos brasileiros registraram os países da América Latina 
BARBOSA, Carlos Alberto Sampaio. Fotojornalistas brasileiros em época de ditadura: entre a estabilidade e o compromisso. Domínios da imagem, v. 13, n. 24, p. 86-103, jan./jun. 2019.

entre as décadas de 1960 e 1980? Qual a relação entre fotógrafos e meios de imprensa? Sofreram algum tipo de censura? Quais são os principais temas retratados? Quais as abordagens propostas? Ocorreram intercambio com fotógrafos latino-americanos? Ocorreram mudanças nos padrões visuais entre cada um dos períodos?

\section{Fotografia brasileira durante a ditadura militar - balanço e transformações}

Entre o final da Segunda Guerra Mundial e o Golpe de 1964 a fotografia documental era marcada pelas chamadas revistas ilustradas cujo maior expoente era a revista O Cruzeiro publicado pelo grupo Os Diários Associados. Esta publicação embora tenha sida criada em 1928 apenas na década de 1940 torna-se a revista mais moderna do Brasil (COSTA, 2012). Essa transformação ocorreu muito em função da atuação de Jean Manzon (19151990). Repórter fotográfico francês que havia trabalhado nas revistas Vu, ParisSoir e Paris Match. Veio para o Brasil para trabalhar no DIP (Departamento de Imprensa e Propaganda), mas logo depois é contratado pela O Cruzeiro. Ele vai revolucionar a revista seguindo o modelo da Life. A publicação salta de 48.000 exemplares para mais de 600.000 na década de 1950. A morte de Getúlio Vargas foi um recorde de tiragem da revista atingindo a cifra de 720 mil exemplares. Em 1951 ele sai da O Cruzeiro e vai para a revista Manchete. A revista $O$ Cruzeiro em seu apogeu contava com cerca de 40 fotógrafos só na sua sede na cidade do Rio de Janeiro.

As empresas de comunicação durante a década de 1950 passam a investir numa administração mais racional, adotando critérios de qualificação profissional para compor seus quadros nos moldes dos veículos de comunicação dos Estados Unidos. O jornalista devia então deixar de ser um profissional liberal autoditada, pois seu ofício agora é lidar com a informação de forma profissional. Essas mudanças também passavam pelo campo das lentes fotográficas. 
BARBOSA, Carlos Alberto Sampaio. Fotojornalistas brasileiros em época de ditadura: entre a estabilidade e o compromisso. Domínios da imagem, v. 13, n. 24, p. 86-103, jan./jun. 2019.

O Jornalismo de influência francesa, opinativo, predominante na imprensa até então, foi aos poucos substituído pelo estilo norte-americano, mas objetivo e investigativo. Em termos visuais, tudo era ainda muito precário: os jornais apresentavam apenas algumas ilustrações e poucas fotografias. (Coelho, 2012, 109).

Quais os temas principais da fotografia documental de então? Assim como a historiografia e a literatura o debate em torno da identidade nacional perpassa essas imagens fotográficas. O ponto de partida foi o Barroco Mineiro aqui se destaca fotógrafos como outro francês Marcel Gautherot (1910-1996) que trabalhou para o SPHAN (Serviço de Patrimônio Histórico e Artístico Nacional depois IPHAN) e temas como a cultura de origem africana que foi registrada por Pierre Verger (1902-1996); o tema dos povos indígenas foi registrado por nomes como José Medeiros (1921-1990) que com suas imagens vai colaborar para a criação do Parque Nacional do Xingu em 1961. As temáticas urbanas com la dolce vida de Copacabana no Rio de Janeiro ou a construção da nova capital em Brasília foram registrados pelas lentes de Thomas Farkas (1924 - 2011 1) fotógrafo de origem húngara.

Na década de 1950 e os primeiros anos de 1960 as fotografias cujo tema era a América Latina estampadas na imprensa comercial brasileira em geral reforçavam os estereótipos negativos: espaço dos golpes, das rebeliões, da instabilidade política e dos ditadores. Essa representação recebeu uma nova camada de interpretação com a Revolução Cubana como nos apresenta Rafael Baitz (2003), a vitória dos "barbudos de Sierra Maestra" num primeiro momento foi saudada como heroica, para logo em seguida com a declaração de que o regime era socialista em 1961, passou a ser retratada como um Estado violento e tirânico, símbolo do perigo vermelho e uma sombra sobre o continente. No Brasil após o Golpe de Estado de 1964 e a instauração do regime militar o país e o fotojornalismo se transformam, surgem novos periódicos e ocorre uma reorganização na profissão do fotógrafo de imprensa. 
BARBOSA, Carlos Alberto Sampaio. Fotojornalistas brasileiros em época de ditadura: entre a estabilidade e o compromisso. Domínios da imagem, v. 13, n. 24, p. 86-103, jan./jun. 2019.

O campo da fotografia documental e do fotojornalismo brasileiro passa por profundas transformações entre as décadas de 1960 e 1980. Como afirma Charles Monteiro (2015, p. 3) "O campo da fotografia no Brasil nos anos 1970 se caracterizou por um processo de expansão, profissionalização, ao mesmo tempo que se fez mais complexo, tanto no campo periodístico como no campo artístico". Esse processo decorria de diversos fatores intrínsecos ao meio fotográfico e sua relação com a situação social e política brasileira.

Vamos aqui apenas indicar alguns tópicos para balizar o debate. Entre o final da década de 1950 e inícios da de 1960 os grandes jornais brasileiros passaram por reformas editoriais e gráficas que privilegiaram a fotografia. Os primeiros a fazerem alguma modificação foram os diários última Hora, Diário Carioca e a Tribuna da Imprensa. Mas o maior impacto foi a reforma do Jornal do Brasil entre 1956 e 1960 (Munteal \& Grandi, 2005, p. 92). Em 1962 era inaugurada a primeira editoria de fotografia. No âmbito técnico temos a transição definitiva das câmeras do tipo Rolleiflex de grande formato para as reflex de pequeno formato como a Leica e a Nikon F. Por fim a valorização da fotografia como uma linguagem na imprensa é referendada pela criação em 1961 do Prêmio Esso de Fotografia. Concurso que consagrava o repórter fotográfico brasileiro

Ao mesmo tempo em que surgia uma nova geração de fotógrafos comprometidos com a valorização da profissão e com a luta contra a ditadura militar, muitos desses fotógrafos ao lado de jornalistas atuam na imprensa alternativa ou sindical que desafiava a censura. Os fotógrafos vivem um processo de organizam sindical e política. Uma das formas para terem mais liberdade de atuação é a criação de cooperativas, coletivos e agências fotográficas. Será ainda nesse momento que teremos os primeiros cursos regulares de fotografia tanto ao nível técnico como superior. Em 1969 a profissão de jornalista é regulamentada em conjunto com a de repórter fotográfico.

Nesse período São Paulo passa a ser o centro editorial brasileiro em detrimento ao Rio de Janeiro. A capital paulista passa a publicar um maior número de revistas com destaque para a Editora Abril que começa a publicar 
BARBOSA, Carlos Alberto Sampaio. Fotojornalistas brasileiros em época de ditadura: entre a estabilidade e o compromisso. Domínios da imagem, v. 13, n. 24, p. 86-103, jan./jun. 2019.

revistas como Realidade (1966-1976), Veja (1968), Quatro Rodas (1960) e Placar (1970). Todas com grande importância do ponto de vista visual, pois utilizavam muitas fotografias e as duas primeiras de grande impacto político. (BARBOSA, 2007)

Os veículos de comunicação, plataforma de difusão como a própria Realidade que falamos anteriormente já utilizava amplamente a fotografia colorida para competir com a Televisão. Outra publicação de destaque é a revista Veja. Fundada em 1968 pelo Grupo Abril inspirada na revista Time americana, enquanto que, Isto É, fundada em 1976 por um grupo de jornalistas dissidentes da Veja, guarda semelhança com a revista Newsweek. (PROENÇA, 2015, 2). O Jornal da Tarde, ou simplesmente JT, era um diário vespertino idealizado por Mino Carta em 1966 e durou até 2012 quando encerrou suas atividades. Foi um dos primeiros jornais a utilizar a escola do new journalism, primeiro a ter um editor de fotografia e marcou época pelas inovações gráficas. Estes periódicos conformam um circuito de divulgação das fotografias documentais.

Essas mudanças criaram uma nova fotografia documental que unia informação e expressão que propuseram novas temáticas na linguagem fotográfica brasileira (FERNANDES JR, 2003). Esse período marca a passagem da Fotografia-Documento para a Fotografia-Expressão para usar as afirmações de Andre Rouillé (2009). Se a fotografia documento seria uma transparência da realidade, confundem-se com as coisas do mundo e por vezes a substituem. A fotografia-expressão trata-se de uma fotografiadocumento que e assim interpreta o acontecimento e não o representa.

Neste sentido, Rovillé defende a reportagem dialógica ao fotojornalismo. Esta não procuraria "representar, registrar, capturar aparência, mas exprimir situações humanas que ultrapassem amplamente a ordem do visível" (ROUILLÉ, 2009, p.184). A função de testemunha do fotógrafo se transforma, ao invés de reproduzir o visível, a proposta é tornar visível; criar novas formas de representar a realidade "não fotografar 'as' coisas ou 'as' pessoas, mas fotografar os estados de coisas e com as pessoas" (ROUILLÉ, 2009, p.184). 
BARBOSA, Carlos Alberto Sampaio. Fotojornalistas brasileiros em época de ditadura: entre a estabilidade e o compromisso. Domínios da imagem, v. 13, n. 24, p. 86-103, jan./jun. 2019.

Embora o tema da política continuasse a receber uma importante atenção tanto na cobertura dos "ritos do poder" em Brasília e nas capitais brasileiras, novos temas chamavam a atenção dos fotógrafos e editores das revistas, como os trabalhadores sem terra, indígenas, a questão do menor abandonado, à seca no nordeste, a reorganização sindical e as greves no $A B C$ paulista, assim como as minorias e as questões urbanas.

Um dos temas que merecem um amplo espaço está ligado as editorias internacionais neles estão inseridos os acontecimentos políticos latinoamericanos. A América Latina será uma das temáticas que receberá atenção especial dos editores e fotógrafos brasileiros durante o período do Regime Militar (1964-1985).

\section{Pedro Martinelli e a cobertura da vitória Sandinista}

Pedro José Martinelli (Santo André, SP, 1950) começou a trabalhar na Gazeta Esportiva (1967) depois no Diário do Grande ABC e nos jornais O Globo e O Estado de S. Paulo. Será no começo dos anos 1970 que em conjunto com antropólogos e os irmãos Villas-Boas começa a percorrer a Amazônia e documenta pelo jornal O Globo o contato com os chamados "índios gigantes" expedição que recebe o nome de Kranhacãrore e que fez contato com os índios Panará então. Foi editor de fotografia da revista Veja entre 1976 e 1983 posteriormente diretor de serviços fotográficos da Editora Abril até 1994. Com um forte caráter documental suas imagens registram o homem comum, as camadas populares, em especial o homem e o ambiente amazônico, mas temas como os esportes (Copas do Mundo, Jogos Pan-americanos e Olímpicos), eventos políticos, sociais e aspectos urbanos compõem também seu olhar. (Coelho, 2012, p. 244-248).

Será na revista Veja que ele mais irá trabalhar em nosso continente. Vejamos brevemente essa revista. A revista Veja criada em 1968 no modelo das revistas semanais de informação similares às norte-americanas Time e Newsweek. Victor Civita era diretor e editor da Abril, Roberto Civita diretor de publicações, e Mino Carta como diretor de redação. Ao contrario das revistas 
BARBOSA, Carlos Alberto Sampaio. Fotojornalistas brasileiros em época de ditadura: entre a estabilidade e o compromisso. Domínios da imagem, v. 13, n. 24, p. 86-103, jan./jun. 2019.

ilustradas da fase anterior ( $O$ Cruzeiro, Manchete e Realidade) em que a fotografia era predominante, a Veja dava destaque de forma equilibrada entre texto e imagem. Em 1976 o semanário cria a editoria de fotografia uma inovação para o Brasil, mas já utilizada nas revistas internacionais. Em 1979, o editor de fotografia era Sérgio Sade.

A revista Veja em geral era publicada com aproximadamente 100 páginas, com grupos editoriais bem definidos, como as colunas Brasil, Cinema, Comportamento, Economia e Negócios e Internacional para ficar em alguns exemplos. A revista possuía um quadro de fotógrafos considerável com nomes consagrados no Brasil, como: Walter Firmo (Rio de Janeiro), Carlos Namba e Salomon Cytrynowicz (Brasília), Irmo Celso, Sergio Sade e Pedro Martinelli (São Paulo). No que toca a editoria internacional, que mais nos interessa aqui, usa os serviços de agências internacionais como UPI, Associated Press, Paris Match, Latin Reuters e France Press. No miolo da revista, estão os temas em destaque como as editorias de Brasil, Economia \& Negócios e Internacional. Nestas editorias é que a equipe de fotógrafos será mais acionada (Proença, 2015a, p. 57)

Em 1979 Pedro Martinelli após ser enviado para a cobertura do conflito entre a Argentina e o Chile por conta do Canal de Beagle vai para o Caribe a fim de cobrir os Jogos Panamericanos de Porto Rico, e de lá é deslocado para a Nicarágua para registrar a luta da Frente Sandinista de Libertação Nacional que buscava derrubar o governo ditatorial de Anastácio Somoza. Segundo o fotógrafo foi enviado para a Nicarágua porque estava mais próximo dos acontecimentos e não por uma escolha sua. Afirma que foi muito difícil a cobertura da guerra civil, devido as dificuldades técnicas (envio de fotos coloridas, telefoto) e também pelas condições de trabalho em uma zona de conflito. Nessa cobertura estabeleceu contato com fotógrafos das equipes norte-americanas que também estavam cobrindo o conflito como a Newsweek e demais agências internacionais. Vejamos abaixo algumas das suas fotografias estampadas nas páginas da revista Veja. 


\section{Imagem 1}
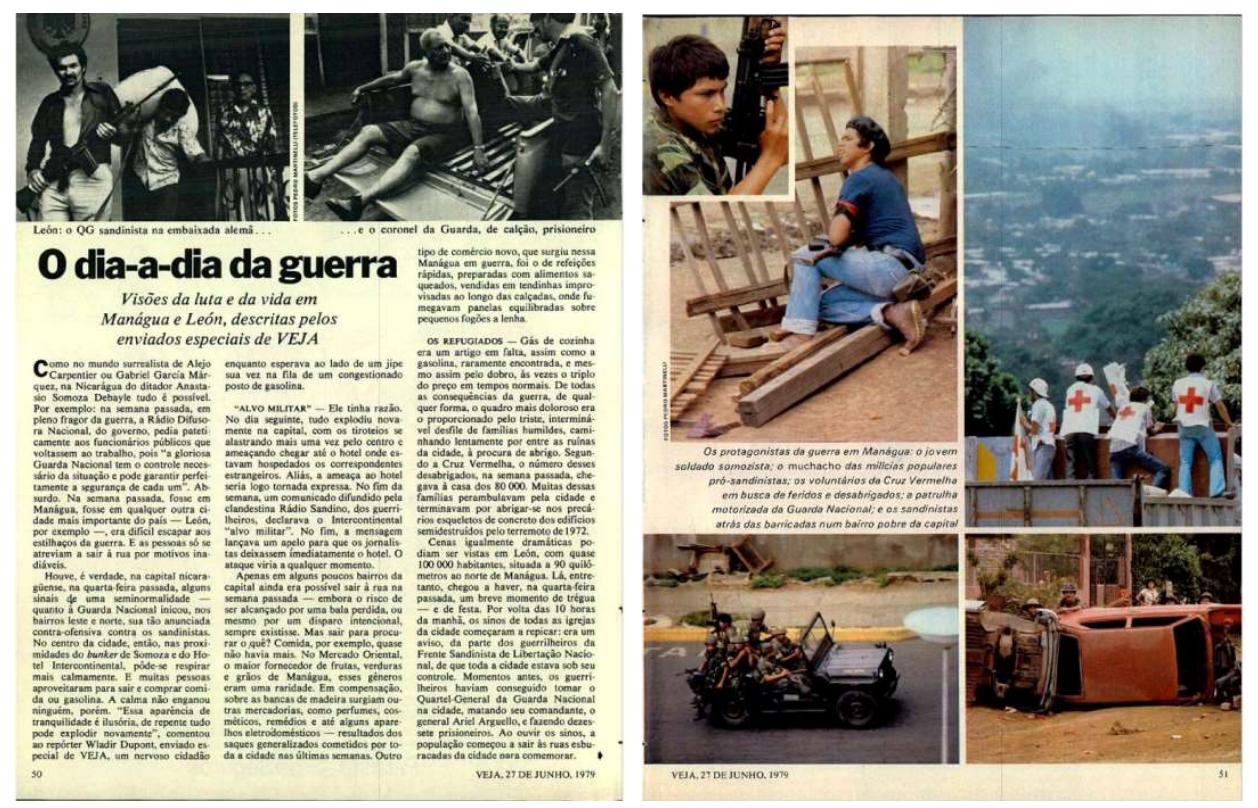

Revista Veja, 27/06/1979 com fotografias de Pedro Martinelli

Seu trabalho aparece em duas edições da revista, na edição de 20 e 27 de junho de 1979. Na primeira reportagem na edição de número 563 de 20 de junho de 1979 a reportagem com título "Tiros, bombas, saques" possui 8 páginas e 14 fotografias em preto-e-branco de Martinelli. Nas reportagens de 27 de junho de 1979 "Crime antes da queda" (Veja, 564, 27/06/1979, p. 44-48) possui 11 imagens em 5 páginas, apenas 4 são de Martinelli as outras são da UPI e fotografias das imagens de TV do assassinado do jornalista Bill Stewart. Já na reportagem seguinte "O dia-a-dia da guerra" (Imagem 1) (Veja, 27/06/1979, p. 50-53) as 12 fotografias são de Pedro Martinelli sendo algumas delas em cor. Foram enviadas via aérea para o Brasil.

Será durante essa cobertura que ocorre um acontecimento que merece uma reflexão com relação à censura, ou melhor, a autocensura, da fotografia do corpo de jornalista Bill Stewart. Pedro Martinelli foi um dos poucos a fotografar o transporte do corpo do repórter Bill Stewart da rede $A B C$ News dos Estados Unidos. A foto foi enviada para o Brasil, mas não hora de publicar o diretor-adjunto da revista Elio Gaspari contrariando o editor de fotografia Sergio Sade, proibiu sua veiculação. Afirmando que "Não, não...isso ai não é foto para o leitor da Veja" (BONI, 2014, p. 259) 
BARBOSA, Carlos Alberto Sampaio. Fotojornalistas brasileiros em época de ditadura: entre a estabilidade e o compromisso. Domínios da imagem, v. 13, n. 24, p. 86-103, jan./jun. 2019.

Essa situação como muito bem explorou Caio Proença (2015a) em seu trabalho demonstra como processo que vai da realização da imagem até as páginas dos periódicos passam por uma série de mediadores. Existem seleções que partem do fotógrafo, passa pelo editor de fotografia, diretores e algumas vezes dos proprietários das publicações. Ademais da existência de uma autocensura e limitações para o trabalho de fotógrafos exporem suas imagens. Será por esse motivo que alguns fotógrafos vão optar por outro caminho, a formação de cooperativas ou agências de fotografia onde possuíam maior autonomia em seu trabalho. Vejamos o caso do fotógrafo Juca Martins.

\section{Juca Martins e Jesus Carlos - América Latina como tema}

Nascido em Barcelos, cidade berço de Portugal em 1949, Juca Martins, ou melhor, Manoel Joaquim Martins Lourenço, veio com sua família para o Brasil em 1957. Filho de país trabalhadores teve sua formação na escola técnica da gráfica da Abril em 1967. A Editora Abril já nesse período era um dos principais conglomerados de mídia do país e marcava, como falamos anteriormente, a transição da hegemonia do parque editorial paulista em substituição a capital carioca. Trabalhou na gráfica e depois nos laboratórios fotográficos da editora até se tornar fotógrafo profissional por volta do inicio da década de 1970. (FERNANDES JR, 2015)

Trabalhou para diversos jornais tais como Folha de S. Paulo, Última Hora e Jornal da Tarde e revistas da Editora Abril como Realidade, Quatro Rodas, Veja, Placar e Visão. Em 1975 foi o produtor gráfico e editor de arte do jornal alternativo Movimento. Já nessa época Juca Martins optou por atuar de forma livre, como fotógrafo independente (que alguns chamam de freelancer).

Entre 1977 e 1978 foi colaborador fixo da revista Isto É. Essa revista foi uma experiência inovadora no jornalismo brasileiro, visto que o diretor de redação permitia que os negativos ficassem de pose do autor depois de sua utilização na publicação. Juca desde muito cedo se preocupou com o seu ofício e na organização da classe participando do Sindicato dos Jornalistas e 
BARBOSA, Carlos Alberto Sampaio. Fotojornalistas brasileiros em época de ditadura: entre a estabilidade e o compromisso. Domínios da imagem, v. 13, n. 24, p. 86-103, jan./jun. 2019.

na formação da Associação dos Artistas Gráficos e Fotógrafos (AGRAF). Essa experiência levou-o a criar junto com Nair Benedicto, Ricardo Malta e Delfim Martins - seu irmão - a Agência F4 de fotojornalismo.

A agência F4 foi um marco no fotojornalismo brasileiro. Partia de um projeto calcado num fotojornalismo independente e autônomo das demandas das pautas fechadas de jornais e revistas, o que possibilitava ao fotógrafo trabalhar temas e ensaios que mais the interessasse. A agência, muito por conta de que seus fotógrafos procuravam produzir um fotojornalismo compromissado. O Brasil vivia um período muito rico de movimentos sociais e de contestação ao regime militar. A agência assumia os interesses dos fotógrafos na medida em que permitia que sua produção ficasse em sua posse, que estabelecia uma tabela de preços, ou seja, o autor da imagem mantinha controle da sua produção. A F4 também foi responsável pela edição de dois livros A greve do $A B C$ e A questão do Menor ambos em 1980. Estas publicações são uma representação da proposta de uma atuação compromissada em que o fotógrafo mantinha o controle de suas imagens do começo ao final do processo de difusão. Ambos os livros foram publicados pela Editora Caraguatá na coleção Documenta.

Na virada da década de 1980 para 1990 ocorrem uma séries de mudanças na sociedade brasileira e no campo do fotojornalismo e os fotógrafos da F4 optam por novos caminhos o que leva ao encerramento da agência. Juca e seu irmão Delfim Martins fundam a Pulsar Imagens e depois a Olhar Imagem atuante até os dias atuais.

Juca Martins como fotógrafo autônomo e com seus próprios recursos decide viajar para a América Central (Nicarágua e El Salvador) para primeiro registrar a resistência dos nicaraguenses aos ataques dos grupos conhecidos como "contras" e por conta do aniversário da vitória sandinista. Posteriormente vai a El Salvador acompanhar o desenrolar da guerrilha e as eleições gerais daquele ano. Suas fotografias ilustram diversas publicações nesse período e estampam as páginas do Jornal da Tarde, da revista Veja (capa da edição 704 de 03/03/1982) e Isto É entre fevereiro e abril de 1982. 
BARBOSA, Carlos Alberto Sampaio. Fotojornalistas brasileiros em época de ditadura: entre a estabilidade e o compromisso. Domínios da imagem, v. 13, n. 24, p. 86-103, jan./jun. 2019.

As fotografias publicadas no Jornal da Tarde nessa época não tinham a indicação de autoria. Podemos aferir que eram de Juca Martins pelo cruzamento com as publicadas na revista Isto É e pelas imagens semelhantes que podemos consultar no banco de dados da agência Olhar Imagens. Na revista Isto É ele publica nas reportagens "No cenário da luta", "Rumo ao imprevisível - a crise na América Central se amplia e tende a sair do controle" e especialmente em "O veneno das urnas: guerrilha, Estados Unidos - todos perderam com as eleições". Nessa última reportagem ilustradas com 8 fotografias de Martins muitas são as mesmas ou similares as publicadas no JT ' .

\section{Imagem 2 e 3}
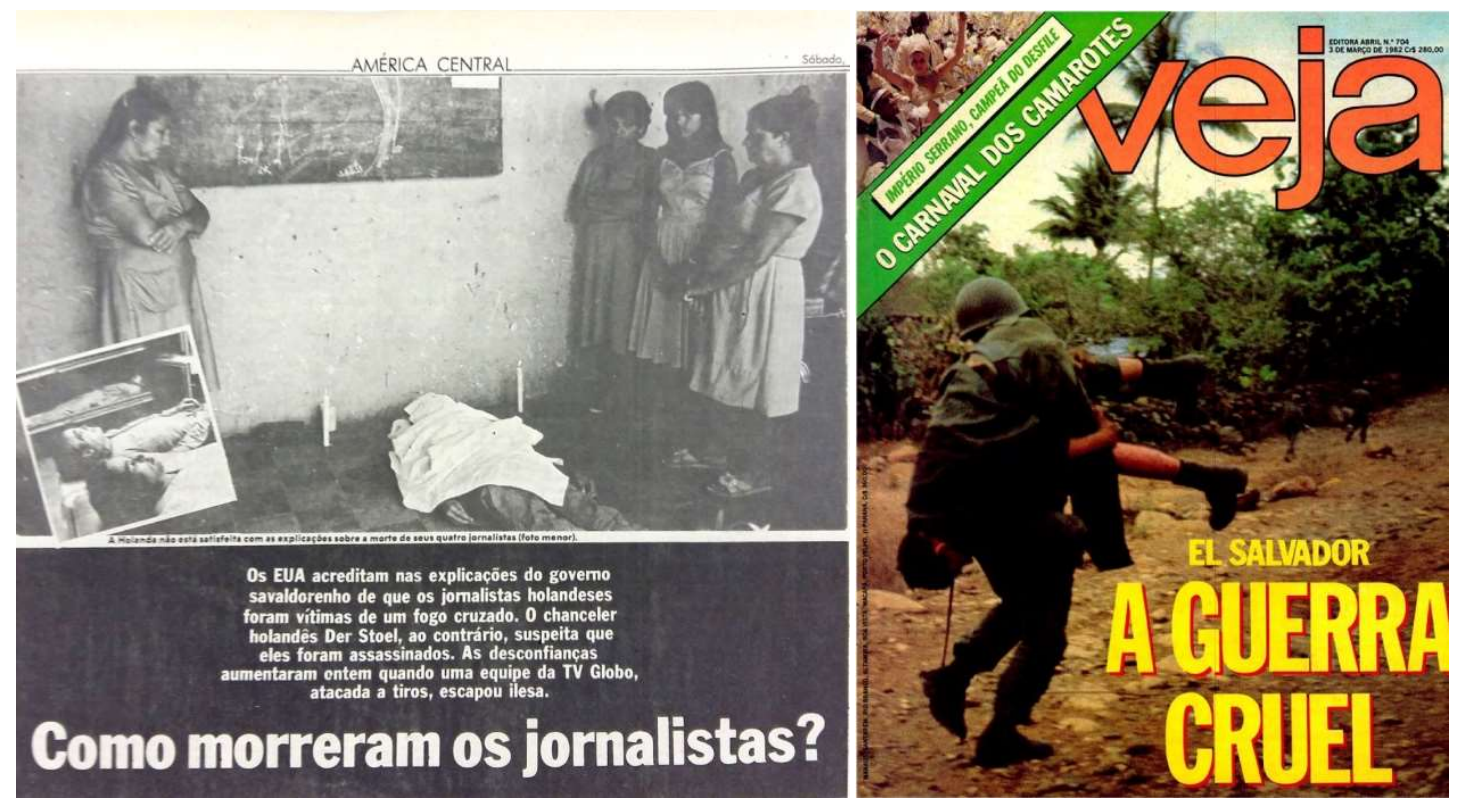

Fotografia de Juca Martins no Jornal da Tarde e revista Veja

As fotografias de Juca Martins que retrataram os conflitos em El Salvador registram temas como a violência do conflito com destaque para as imagens de soldados e da população civil executada, mortos e feridos em combate, os hospitais. Seu olhar se volta também ao cotidiano da população, tanto

\footnotetext{
1 Revista Isto É, 03/03/1982, n 271, "No cenário da luta", pp. 48-56 fotografias de Claudio Edinger, Juca Martins e das agências UPI, Gamma, Sigla. Isto É n 274, 24/03/1982, "Rumo ao imprevisível - a crise na América Central se amplia e tende a sair do controle", pp. 59-60; Isto É, 07/04/1982, n² 276, "O veneno das urnas: guerrilha, Estados Unidos - todos perderam com as eleições", fotografias de Juca Martins e Claudio Edinger.
} 
BARBOSA, Carlos Alberto Sampaio. Fotojornalistas brasileiros em época de ditadura: entre a estabilidade e o compromisso. Domínios da imagem, v. 13, n. 24, p. 86-103, jan./jun. 2019.

urbana como camponesa vivendo em meio as tragédias da guerra civil. Registrou também as eleições de março de 1982. Destaque especial para as fotografias das crianças e jovens. Seu olhar humano revela como jovens e adolescentes participam da guerrilha ao mesmo tempo em que revela os danos causados às crianças em meio ao conflito.

O Brasil entre os anos finais das décadas de 1970 e inicio dos 1980 passava por transformações políticas. Ocorre a chamada abertura política com a anistia e consequentemente volta dos exilados; são realizadas eleições para os governos estaduais e prefeituras das capitais surgem um novo sindicalismo e ao mesmo tempo em que novos movimentos sociais se organizam. Estas transformações permite o surgimento de novos partidos políticos com destaque para o Partido dos Trabalhadores (PT). Nesse contexto me parece que há um novo interesse por processos similares que passavam nossos vizinhos que viviam movimentos similares de redemocratização e lutas contra as ditaduras (Argentina, Uruguai, Chile, Nicarágua e El Salvador). Todo isso transforma nosso continente um tema bastante recorrente nos veículos de comunicação.

A trajetória pessoal e profissional de Jesus Carlos de Lucena Costa se mistura com o contexto brasileiro dos anos 1960 a 1980. Originário de Recife mas logo a família se muda para João Pessoa na Paraíba. Nos finais da década de 1960 milita na no movimento estudantil e se aproxima de grupos de esquerda. Aprende a fotografar com seu pai, fotógrafo lambe-lambe e com um amigo deste. Procurado pela polícia vive clandestino em Fortaleza, Belo Horizonte até se estabelecer em São Paulo. Com seus conhecimentos fotográficos realiza trabalhos como fotógrafo ambulante produzindo e vendendo álbuns e pôster escolares, monóculos com fotografias, fotografias individuais de pessoas no carnaval e fotografias em cabarés.

Em meados dos anos 1970, já em São Paulo passa a atuar na região sul da cidade e no $A B C$, centro da indústria automobilística brasileira de então e palco do novo sindicalismo. Atua também no movimento operário, movimento popular contra a carestia e junto a grupos de católicos operários. Torna-se fotojornalista em finais dos anos 1970 quando passa atuar em jornais 
BARBOSA, Carlos Alberto Sampaio. Fotojornalistas brasileiros em época de ditadura: entre a estabilidade e o compromisso. Domínios da imagem, v. 13, n. 24, p. 86-103, jan./jun. 2019.

como Em Tempo, Repórter, ABCD Jornal e a Folha Bancária do sindicato dos Bancários de São Paulo. Segundo o próprio fotógrafo foi nesse período entre 1978 para 1979 que começa a viver como fotojornalista. Registra com suas lentes a organização do movimento sindical dos metalúrgicos do $A B C$ e as greves que marcaram o final dos desta década.

Envolve-se ativamente com a fotografia e as transformações que o ofício passa nesse momento. Vende imagens para a Folha de São Paulo, $O$ Estado de S. Paulo, Veja e Isto É. Participa do movimento que transforma a fotografia de então com o uso das lentes grande angulares e o abandono do flash além da formalização da profissão de repórter fotográfico e a consolidação da tabela de preços das fotografias e da luta pelo direito autoral nas publicações ilustradas. Chega a trabalhar para as agências e coletivos fotográficos de então como a $\mathrm{F} 4$.

Motivos pessoas e uma busca de novas experiências o levam para o México em 1982 como correspondente da agência SIGLA. No México devido aos contatos que possuía no Brasil rapidamente começa a trabalhar. Sua primeira atividade é cobrir a campanha presidencial da candidata Rosário Ibarra de Piedra do Partido Revolucionário dos Trabalhadores. Mas em pouco tempo estabelece contatos com os fotógrafos mexicanos como Pedro Valtierra, Francisco Mata, Marco Antonio Cruz, Nacho Lopez, Pedro Meyer e tantos outros. Segundo ele será efetivamente no México que passa a conhecer a fotografia latino-americana inclusive o já lendário fotógrafo cubano Korda².

Durante seu período no México realiza diversas exposições e trabalhos que foram publicados em revistas como Claudia e Casa e Jardim, em periódicos como Bandeira Socialista, El Día, Ovaciones e El Universal. Participa da fundação do jornal La Jornada e da agência fotográfica Imagenlatina. Em 1987 decide retornar para o Brasil mas sua volta é uma grande jornada pela América Latina passando por El Salvador, Nicarágua, Colômbia sempre com

\footnotetext{
2 Alberto Díaz Gutiérrez, conhecido como Alberto Korda ou somente Korda (1928-2011) ficou mundialmente conhecido devido a sua fotografia de Ernesto "Che" Guevara. Denominada de Guerrilheiro Heroico, tornou um ícone visual.
} 
BARBOSA, Carlos Alberto Sampaio. Fotojornalistas brasileiros em época de ditadura: entre a estabilidade e o compromisso. Domínios da imagem, v. 13, n. 24, p. 86-103, jan./jun. 2019.

uma mirada engajada, voltada para captar as lutas de grupos políticos de esquerda em nosso continente.

\section{Entre Estabilidade, Independência e Compromisso}

Os fotógrafos aqui apresentados representam muito bem as transformações por que passou o fotojornalismo brasileiro durante o regime militar e a situação dessa categoria. Enquanto que Pedro Martinelli em grande parte de sua atuação como fotojornalista era um fotógrafo fixo da revista Veja, Juca Martins trabalhou de forma autônoma vendendo suas imagens através da agência F4. Martinelli é enviado para cobrir os jogos panamericanos e deslocado para registra os conflitos da Nicarágua. Juca Martins de forma independente e com recursos próprios decide ir para América Central fazer a cobertura dos conflitos em El Salvador. Os dois fotógrafos possuem um olhar que procura além de registrar as tradicionais cenas de violência (guerrilheiros e soldados, mortes e feridos em meio aos conflitos), mas o cotidiano da população em meio à revolução. Eles reafirmam a ideia do "fotógrafo heroico" que arriscando sua vida para procurar a melhor fotografia do conflito.

No que toca a representação da América Latina, censura e seleção das imagens, podemos afirmar que embora os fotógrafos tenham procurado produzir uma representação da América Latina distinta da anterior, prevaleceu a imagem do continente conflituoso, palco de guerras, revoluções e da instabilidade política. A narrativa não foi construída apenas pelos fotógrafos, mas também pelos editores e diretores de redação. No que diz respeito à censura, ainda que o Brasil passasse por uma abertura política ela continuava a existir como fica evidenciado pelo caso de Martinelli na Veja, se bem que, no caso seja uma autocensura da revista personificada na figura do seu diretor-adjunto.

Por seu turno Jesus Carlos optou por um caminho mais radical, intercalou seu ofício a luta ativa contra a ditadura. Viveu as transformações do final dos anos 1970 no campo do fotojornalismo e a luta pela democracia de forma 
BARBOSA, Carlos Alberto Sampaio. Fotojornalistas brasileiros em época de ditadura: entre a estabilidade e o compromisso. Domínios da imagem, v. 13, n. 24, p. 86-103, jan./jun. 2019.

militante. Sua trajetória é mais radical, pois não apenas se interessa em fotografar o que se passa na América Latina, mas escolhe vivenciar a experiência no México. Lá também se insere na mesmo grêmio de fotógrafos de imprensa tendo participação destacada como na luta dos movimentos de esquerda como a cobertura da campanha de Rosario Ibarra.

Com sua bagagem brasileira leva novas propostas como a fundação de agências fotográficas e de periódicos como é o caso da Imagemlatina e do La Jornada. Ele é um exemplo de um mediador dentro desse campo ao transitar entre Brasil e México. Ao contrário de outros colegas como Juca Martins e Pedro Martinelli sua atuação no mundo latino-americano transcende apenas de um olhar externo, pois procura uma olhar da realidade latino-americana desde dentro. Atualmente vive em São Paulo onde trabalha para sindicatos e movimentos populares. Jesus é um exemplo de um fotógrafo militante que levou ao extremo sua opção de independência.

O fotógrafo Evandro Teixeira, um dos mais destacados fotojornalistas brasileiros, dirá sobre essa época "Minha arma foi minha câmera fotográfica. Com ela eu subi em palanques, entrei em palácios e em presídios, corri, apanhei, mas eu precisava registrar aquilo tudo, precisava deixar documentos para a história" (TEIXEIRA, 2012, p.244). Neste sentido e como podemos ver expresso nesse texto, os profissionais da lente não só registraram os fatos senão que se converteram em um dos fatores que contribuíram tornar possível a transição democrática no Brasil e atuaram na construção de uma memória e cultura visual do período.

Segundo afirma Alberto Del Castillo (2017) pensando o contexto do fotojornalismo argentino, mas que creio ser possível transplantar para 0 universo brasileiro durante o regime militar, a fotografia e em particular 0 fotojornalismo desempenhou um papel muito relevante em todo o processo de resistência aos governos autoritários, registrando episódios e construindo as condiciones de visibilidade de diversos atores políticos e sociais dessa etapa de nossa história. Personagens que de outra forma poderiam ser esquecidos ou apagados. Os fotógrafos usaram suas câmeras como arma na construção de um imaginário e uma cultura visual durante o regime militar no Brasil. 
BARBOSA, Carlos Alberto Sampaio. Fotojornalistas brasileiros em época de ditadura: entre a estabilidade e o compromisso. Domínios da imagem, v. 13, n. 24, p. 86-103, jan./jun. 2019.

Os fotógrafos tiveram um papel protagônico neste processo, já que não se limitaram a registrar os protestos e as mobilizações sociais, senão que se converteram em atores poderosos, convertendo as suas fotografias em "veículos de memória", pelo fato de considerar que o uso das imagens fotográficas ultrapassou seu papel tradicional de registro para se converter em parte do processo político de resistência política, social e cultural.

\section{Referências}

CASTILLO TRONCOSO, Alberto del. Fotografía y memoria. Conversaciones con Eduardo Longoni. Buenos Aires/México: FCE/Instituto de Investigaciones Dr. José María Luis Mora, 2017.

BAITZ, Rafael. Um continente em foco: a imagem fotográfica da América Latina nas revistas semanais brasileiras (1954-1964). São Paulo: Humanitas, 2003.

BARBOSA, Marialva. História cultural da imprensa: Brasil 1900-2000. Rio de Janeiro: Mavad X, 2007.

BONI, Paulo César. Entrevista: Juca Martins. Discursos Fotográficos, Londrina, v. 10, n. 17, p. 209-228, jul./dez, 2014.

BONI, Paulo César. Entrevista: Pedro Martinelli. Discursos Fotográficos, Londrina, v. 10, n. 16, p. 239-266, jan./jun. 2014.

COELHO, Maria Beatriz. Imagens da nação: brasileiros na fotodocumentação de 1940 até o final do século XX. Belo Horizonte/São Paulo: Editora da UFMG/Imesp/Edusp, 2014.

COSTA, Helovise, Entre o local e o global: a invenção da revista O Cruzeiro. In: COSTA, Helouise; BURGI, Sergio. As origens do fotojornalismo no Brasil: um olhar sobre O Cruzeiro. São Paulo: Instituto Moreira Salles, 2012. p. 9-31.

FERNANDES JR., Rubens. Juca Martins: a eterna paixão pela aventura humana. In: SIQUEIRA, Henrique (Org.). Juca Martins. São Paulo: Editora WMF Martins Fontes, 2015.

FERNANDES JR., Rubens. Labirinto e Identidade: panorama da fotografia no Brasil - 1946 - 98. São Paulo: Cosac \& Naify, 2003.

MONTEIRO, Charles, El campo de las fotografías y las imagenes del Brasil en los años 1970-1980: entre el fotoperiodismo y la fotografía documental.

Artelogie, n. 7, p. 1-15, avril 2015. Disponível em: http://cral.in2p3.fr/artelogie/spip.php?article353. Acesso em: 26 dez. 2019. 
BARBOSA, Carlos Alberto Sampaio. Fotojornalistas brasileiros em época de ditadura: entre a estabilidade e o compromisso. Domínios da imagem, v. 13, n. 24, p. 86-103, jan./jun. 2019.

MUNTEAL, Oswaldo; GRANDI, Larissa. A imprensa na história do Brasil:

Fotojornalismo no século XX. Rio de Janeiro: Editora da PUC-Rio/Desiderata, 2005.

PROENÇA, Caio de Carvalho. Fotografias do fotojornalismo no Brasil anos 1970: aproximações e distanciamento em Veja, Isto É, Time e Newsweek. In: Anais Eletrônicos do XXVIII Simpósio Nacional de História - Lugares dos Historiadores: velhos e novos desafios. Florianópolis: Anpuh, 2015b. p. 1-16.

PROENÇA, Caio de Carvalho. O conflito da Nicarágua em 1979 em Veja: o trabalho do fotógrafo e as decisões editorais. Mouseion, Canoas, n. 21, p. 5170, ago. 2015a.

ROUILLÉ, André. A fotografia: entre documento e arte contemporânea. São Paulo: Editora Senac, 2009.

TEIXEIRA, Evandro. A fotografia a serviço da luta contra a ditadura militar no Brasil. Discursos Fotográficos, Londrina, v. 8, n. 12, p.217-252, jan./jun. 2012. 